INTERNATIONAL JOURNAL OF RESEARCHES IN BIOSCIENCES, AGRICULTURE \& TECHNOLOGY ○ VISHWASHANTI MULTIPURPOSE SOCIETY (Global Peace Multipurpose Society) R. No. MH-659/13(N) www.vmsindia.org

\title{
PREVALENCE OF TAPEWORM TYLOCEPHALUMSALUNKHI N.SP. IN MARINE FISH TRYGONSEPHEN (CUVIER, 1871) FROM RATNAGIRI DISTRICT (MS) INDIA.
}

\author{
${ }^{1}$ Supugade V., ${ }^{1}$ Pawar S.M. and ${ }^{2}$ Dhole J. \\ ${ }^{1}$ Lal Bahadur Shastri College of Arts, Science and Commerce, Satara (M.S) India \\ ${ }^{2}$ Dr. Babasaheb Ambedkar Marathwada University, Aurangabad (M.S) India \\ Email: supugadevb26@gmail.com
}

\begin{abstract}
This present paper aimed to study the prevalence of tapeworm Tylocephalum salunkhi n.sp. in Marine fish Trygon sephen (Cuvier, 1871) fromfrom Ratnagiri District during July 2004 to June 2007. A total of 414 numbers of Trygonsephenhas been sampled for the heminthic infection in which 151 fishes $(36.47 \%)$ has been found to be infected with 274 tapeworm were recovered from different organs of the fishes, with the highest number recoded in the intestine. The high prevalence of tapeworm recorded in summer season moderate in winter and least in monsoon.
\end{abstract}

Keywords: Prevalence, Tapeworm, Marine fish, Ratnagiri

\section{Introduction:}

Fish is an important item of human food as well as the source of income of a segment of the population. These edible fishes are known to harbour a number of tapeworm which cause deterioration in their health, hence their market and nutritive value is affected. Parasitism is undoubtedly an ecological relationship between two different populations. Noble and Noble, 1976 stated that parasitism is an association of two organisms of different species, in which one is benefited and other harmed. The organism, which is benefited, is the parasite and that which suffers, is the host.

Fish parasitic populations are known to differ, due to variation in the environment and host population (Dogiel, 1961). For most of the fish parasites it is difficult to know, whether differences such as the presence or absence of parasites prevalence, intensity, density and index of infections, are due to the environmental factors or due to differences in host species, composition and their density (Koskivara et. al., 1991). Environmental conditions and host behavior influenced by habitat and seasonal, while physical state reflect internal conditions, through this may be affected by external factors. Population investigation can provide data for prediction of integrated methods to achieve the regulation of numbers of harmful parasites (Kennedy, 1977).

The aim of studying the population and community ecology of fish parasites is to determine their natural modifications, including both biotic and abiotic factors of the host-parasite system that affect its dynamics (George-Nascimento, 2002). A large number of processes have been suggested to influence the seasonal variation in parasite communities in temperate regions, for example, temperature and other abiotic factors, abundance of intermediate hosts, changes in the abundance of hosts, food and reproductive behaviour and host immunity (Chubb, 1979). The infracommunities of parasites of T. lepturus had higher diversity values in the months related to the phenomenon of upwelling and the peak of the reproductive process of the fish, which may be related to the increase in marine productivity in the area studied as well as behavioural and physiological changes occurring in the host in this period (Anderson, 1976).

The present study includes application of statistical methods to understand and distribution of tapeworm both infra and supra population level for Tylocephalum salunkhi n.sp. in three annual cycles from July 2004 to June 2007.

Each annual cycle comprises of:

1) Rainy season (June to September)

2) Winter season (October to January)

3) Summer season (February to May)

\section{Material and Method:}

The marine fishes were collected from different area of Ratnagiri District during the period from July 2004 to June 2007. Fishes were opened up dorso-ventrally and the internal organs examined. The entire 
digestive system was removed and placed in a Petri dish with physiological saline. Infection of each group of parasites was treated as follows: collected tapeworm were first relaxed and then fixed in hot 4\%formalin and stained using Harris haematoxyline. Stained parasites were washed in distilled water, dehydrated in ascending grades of alcohol, cleared in xylene, mounted in D.P.X. Drawings were made using a camera lucida. (Francis Weesner 1964). The identification is made with the help of "Systema Helminthum" by Yamaguti (1961). The data related to percentage of infection, intensity and abundance were determined standard formulae of Hoffmann (1999).

\section{Results and Discussion:}

The present data prevalence of tapeworm Tylocephalum salunkhi n.sp. in Trygon sephen marine fishes were collected from different places of Ratnagiri District during the period of July 2004 to June 2007. The analysis of data shown the occurrence of tapeworm variable in the form of tables, Further with month and year wise with their different habitat.

A total of 414 numbers of Trygonsephenhas been sampled for the heminthic infection in which 151 fishes (36.47\%) has been found to be infected with 274 tapeworm were recovered from different organs of the marine fishes, with the highest number recorded in the intestine. The tapeworm Tylocephalum salunkhi n.sp.there by indicating high prevalence of infection. The prevalence of infection of tapeworm Tylocephalum salunkhi n.sp. the infection was high during summer, moderate in winter and low during the rainy season. The present study it was observed that the incidence of infection increased with host age, infection levels were low in young hosts and showed remarkable infection rise in adults.

In India many workers did the study of population dynamics of helminth parasites from vertebrates. Population investigation can provide data for the predication of integrated methods to achieve the regulation of numbers of harmful parasites, because it has been stated that a single method of control or coordinated activities are of little value, since they ameliorate the infection (Kennedy, 1975,1978). Seasonal fluctuations, locality, age, size and sex of the host also determine the parasitic community diversity and burden. Dogiel et al., 1961 stated that seasonal environmental changes of water such as temperature, $\mathrm{pH}$ and conductivity affect the occurrence of parasites of an aquatic host.

Feeding activity of the host also be one of the reasons for the seasonal fluctuation of infections according to Pennuyuick(1971 a, b) the fishes were infected with large number of parasites in late winter to end of summer months, because the environmental conditions are favorable in such months. The waters are warm but not cold at that time the Zooplankton fauna may be rich, this probably corresponds to the peak in the feeding activity of the fish together with the richness in the intermediate host fauna may be the crustaceans, smaller mollusks and fish resulting in high infections. Thus the temperature and seasons play an important role in the recruitment of parasitic fauna.

Khan et al., (2004) inferred that the prevalence of infection of Diplozoon kashmirensis and Pomphorhynchus in Schizotlhorax was highest during spring, while the minimum value was recorded in autumn whereas Adenoscolex showed a marked seasonal occurrence as the infection was observed only during spring and summer seasons. (Ibiwoye et al., 2004) concluded that fishes are generally susceptible to heavy infestations during rainy season when they are weakened by hibernation. In the findings of the parasite infection showed seasonal variations with the highest prevalence in summer season (Gupta, 2012. Tambe and Dhole, 2011, Bhure, et al., 2014).

External environment factor include seasonal change in temperature \& water .The invasion level may subsequently be moderated by immune defenses, which included host physiological state reproduction, nutrition, age and its experiences of infection (Angali Dhar ,2003, Jaywant Dhole 2010) Importance of the annual seasons was first reported by Bykhovs (1929) who studied the influences 
of various annual seasons on the infection of leaf worm in the Volga district USSR. The field related to incidence and intensity of nematode parasite studied by Mittal (1980). Hoffman (1980) reported that the intestines of infected small fish, such as the golden shiner, become plugged by the worms and in some instances are perforated. Minnow farmers report mortality among infected stocks. Laboratory experiments also demonstrated that mortality caused by tape worms was a function of parasite density and host size. At elevated temperature $(25$ to $30^{\circ} \mathrm{C}$ ), survival of both infected and non- infected fish declined, but infected fish died sooner.

After the analysis of data the present study can be concluded that the high infection of helminth parasites (incidence, intensity, density and index of infection) are occurred in summer seasons followed by winter where as low in monsoon season. This type of results indicated that environmental factors, feeding habitatmorphological, physiologicaland ecological factors are influencing the seasonality of parasitic infection either directly or indirectly and effecting thedistribution of parasites.

Table-1: Prevalence of tapeworm Tylocephalum salunkhi n.sp. from Trygon sephen during the period of July 2004 to June 2007.

\begin{tabular}{|c|c|c|c|c|c|}
\hline Sr. No & $\begin{array}{c}\text { Month \& } \\
\text { Year }\end{array}$ & $\begin{array}{c}\text { No. of } \\
\text { dissected } \\
\text { examined }\end{array}$ & $\begin{array}{c}\text { No. of } \\
\text { infected } \\
\text { hosts }\end{array}$ & $\begin{array}{c}\text { No. of } \\
\text { tapeworm } \\
\text { collected }\end{array}$ & Locality \\
\hline 1 & July 2004 & 15 & Nil & Nil & Bhatye \\
\hline 2 & Aug. 2004 & 10 & Nil & Nil & Harne \\
\hline 3 & Sept. 2004 & 12 & Nil & Nil & Bhagwati \\
\hline 4 & Oct. 2004 & 09 & 02 & 05 & Mirkarwada \\
\hline 5 & Nov. 2004 & 11 & 04 & 07 & Mirkarwada \\
\hline 6 & Dec. 2004 & 16 & 07 & 10 & Bhagwati \\
\hline 7 & Jan. 2005 & 13 & 05 & 14 & Mirkarwada \\
\hline 8 & Feb. 2005 & 08 & 07 & 18 & Harne \\
\hline 9 & March 2005 & 09 & 10 & 20 & Bhatye \\
\hline 10 & April 2005 & 14 & 08 & 15 & Mirkarwada \\
\hline 11 & May 2005 & 11 & 06 & 07 & Bhagwati \\
\hline 12 & June 2005 & 12 & 02 & 01 & Harne \\
\hline 13 & July 2005 & 10 & Nil & Nil & Mirkarwada \\
\hline 14 & Aug. 2005 & 12 & Nil & Nil & Harne \\
\hline 15 & Sept. 2005 & 09 & 02 & Nil & Bhatye \\
\hline 16 & Oct. 2005 & 15 & 04 & 05 & Bhagwati \\
\hline 17 & Nov. 2005 & 11 & 06 & 07 & Mirkarwada \\
\hline 18 & Dec. 2005 & 14 & 07 & 08 & Bhatye \\
\hline 19 & Jan. 2006 & 12 & 05 & 10 & Harne \\
\hline 20 & Feb. 2006 & 10 & 07 & 10 & Mirkarwada \\
\hline 21 & March 2006 & 08 & 09 & 14 & Bhagwati \\
\hline 22 & April 2006 & 13 & 06 & 18 & Harne \\
\hline 23 & May 2006 & 16 & 04 & 07 & Mirkarwada \\
\hline 24 & June 2006 & 08 & 01 & 05 & Harne \\
\hline 25 & July 2006 & 15 & Nil & Nil & Mirkarwada \\
\hline 26 & Aug. 2006 & 10 & Nil & Nil & Harne \\
\hline 27 & Sept. 2006 & 12 & Nil & Nil & Mirkarwada \\
\hline 28 & Oct. 2006 & 11 & 04 & 10 & Bhagwati \\
\hline 29 & Nov. 2006 & 14 & 05 & 11 & Harne \\
\hline 30 & Dec. 2006 & 13 & 08 & 12 & Mirkarwada \\
\hline 31 & Jan. 2007 & 16 & 06 & 13 & Bhatye \\
\hline 32 & Feb. 2007 & 09 & 07 & 11 & Harne \\
\hline 33 & March 2007 & 08 & 08 & 20 & Bhagwati \\
\hline 34 & April 2007 & 10 & 06 & 08 & Mirkarwada \\
\hline 35 & May 2007 & 11 & 04 & 06 & Harne \\
\hline 36 & June 2007 & 07 & 01 & 02 & Bhatye \\
\hline Total & & 414 & 151 & 274 & $\begin{array}{c}\text { Ratnagiri } \\
\text { district }\end{array}$ \\
\hline
\end{tabular}




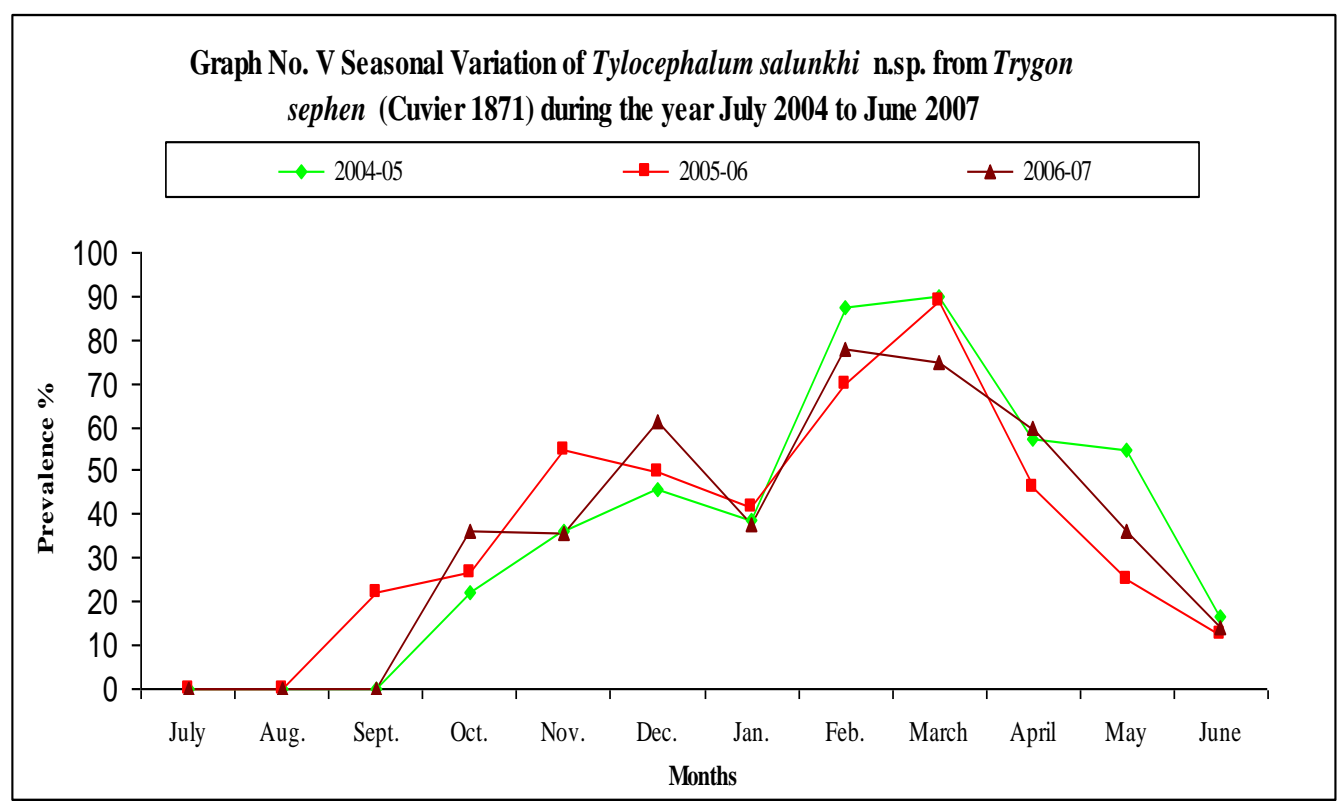

\section{Acknowledgement:}

The authors are thankful to Principal Dr. R.V. Shejwal, L.B.S. College, Satara, for providing all necessary help and encouragements to carry out all experiment.

\section{References:}

Anderson R.M. 1976: Parasitology (72) 281-395

Bhure, D B, Nanware, S S 2014: Studies on Prevalence of Cestode Parasites of Freshwater Fish, Channa punctatus. Journal of Entomology and Zoology Studies. Vol.2(4) pp 283-285.

Chubb, J.C. (1982). Seasonal occurrence of helminth parasite in fishes. Part-iv. Adult Cestoda, Nematoda and Acanthocephala. Advances in Parasitology. Academic press. London \& New york.20: 1-292.

Dobson, AP. and Roberts, M., 1994. The population dynamics of parasitic helminth communities. Parasitology, vol. 109, supl., p. S97-S108.

Dogiel V.A. (1985) Parasitology of fishes. Leningrand university press, Olivear and Boyed, Edinburgh and London. 1-348

George WL, (2002). Angler's guide to fish diseases and parasites. University of George, College of Agricultural and EnvironmentalSciences.

Hoffman, G.L. (1999). Parasites of North American Freshwater Fishes. 2nd ed. Ithaca and London, Comstock Publishing Associates (Cornell University Press).

Jaywant Dhole and Ram Chavan (2010): Survey of helminth parasites in freshwater fishes from Marathwada region, MS, India
Jou of Fish. and Aqua, ISSN: 0976-9927 Vol 1,(1) PP-01-07

Kennedy C.R. (1976) Ecological aspects of parasitology North Holland publishing company Amsterdam 1- 474.

Khalil L. F. and Polling K. (1997) Checklist of the Helminth Parasites of African Freshwater Fishes. Uni. of the North Department of Zoology. Republic of South Africa 184.

Kulakovskaya, O.P.,1962. The seasonal changes in representatives of the family Caryophyllaeidae (Cestoda) under conditions existing in Western Ukrainian region, URSR. Scientific Memories of Science Biological Museum of the Utranisn Academy of Science(10): 88-93.

Lilley, J.H., Philips, M.J. and Tongutai, K. A review of epizootic ulcerative syndrome (EUS) in Asia. Publ. Aquatic Animal Health Research Institute and Network of Aquaculture Center in Asia-Pacific,Bangkok, Thailand. 1992, p. 73.

Linton, E. (1889): Notes on Entozoa of marine fishes of New England. Ann. Rep. U.S. Comm. Fish and Fisheries for 1856 Washington, 1889, 14: 453-517.

Pennyuick, K.L. (1971): "Seasonal Variations in the parasitic population of three spined sticklebacks, Gasterosteusaculeatus L". Parasitology 63, 373-388.

Poulin, R. and Valtonen, E2002. The predictability of helminth community structure in space: a comparison of fish populations. Inter. Jou. for Par., vol. 32, no. 10 , p. 1235-1243. 
Rohde, K., Hayward, C. and Heap, M., 1995. Aspects of the ecology of metazoan ectoparasites of marine fishes. International Journal for Parasitology, vol. 25, no. 8, p. 945-970.

Tambe Dinkar and Jaywant Dhole (2011): Prevalence of heminthic infection in C. hircus from Ahmenagar District. Recent
Research in Sci. and Tech. 2011, 3(3): 37-39 ISSN: 2076-5061

Yamaguti S. (1961): Systema Helminthium, vol. II .Cestode of vertebrates, Interscience publishers INC, New York and London, 1860.

$* * * * * * *$ 